Acta vet. scand. $1981,22,594-596$.

Brief Communication

\title{
STAINING OF CRYPTOSPORIDIA BY A MODIFIED ZIEHL-NEELSEN TECHNIQUE
}

During the past years cryptosporidia have been reported to be associated with neonatal diarrhoea in calves. They have been observed in a number of animal species and in man, possibly causing diarrhoea or contributing to diarrhoea (Pohlenz et al. 1978, Nagy \& Pohlenz 1981). Since they are known to be transmissible between species (Moon \& Bemrick 1981, Heine \& Boch 1981 ) and seem to be widespread among livestock in many countries (Heine \& Boch, Nagy \& Pohlenz) a quick and reliable method for their detection is desirable. In smears stained with Giemsa's stain, which is the stain usually employed for cryptosporidia (Pohlenz et al.), some developmental stages, probably the oocysts, appear as unstained or faintly blue-stained pinchouts. In addition, yeasts occurring in feces can be mistaken for certain stages of these coccidia, as reported by Angus et al. (1981), and thus give rise to differential diagnostic problems.

In order to develop a more effective routine staining method for detection of cryptosporidia in smears of intestinal scrapings or feces, various staining procedures were tried.

While different modifications of the Gram stain proved unsuitable, a modified Ziehl-Neelsen stain was effective in demonstrating these protozoa.

The following procedure was used:

1. dry smear at room temperature;

2. fix in $96 \%$ methanol for $2-5 \mathrm{~min}$;

3. dry at room temperature;

4. fix briefly in flame;

5. stain with concentrated carbol fuchsin for $20-30 \mathrm{~min}$, without heating;

6. rinse in tap water;

7. differentiate with $\mathrm{H}_{2} \mathrm{SO}_{4}$ for $20-60 \mathrm{~s}$ (concentrations from 0.25 to $10 \%$ may be used); 
8. rinse in tap water;

9. counterstain with $5 \%$ malachite green for 5 min;

10. rinse in tap water;

11. dry at room temperature;

12. mount in Eukitt.

In smears stained by this technique cryptosporidia appear as 3-6 $\mu \mathrm{m}$ large, densely stained red bodies clearly distinguishable against a green background. Some of the parasites, however, are rather lightly stained; these are probably oocysts or their precursors. The cryptosporidia contain a varying number of darker blue or brownish internal bodies. The parasites are easily detected at magnifications of $200-400$ times.

The properties of the carbol fuchsin dye may vary, and with certain preparations step 5 in the staining procedure may have to be extended to $1 \mathrm{~h}$ or even overnight. For differentiation (step 7) $\mathrm{H}_{2} \mathrm{SO}_{4}$ may be used in concentrations from $0.25 \%$ to $10 \%$ The most appropriate concentration of the acid and length of the differentiation procedure would seem to depend on the properties of the carbol fuchsin dye. So, before adopting the technique, it is advisable to make a few experiments with positive control smears, in order to adjust steps 5 and 7 to the dye preparation available.

In smears from fecal samples or ileal mucosa scrapings, yeasts were found to be stained by the Giemsa method, but not by the Ziehl-Neelsen method.

In conclusion, we feel that this modified Ziehl-Neelsen staining is a reliable method for detection of cryptosporidia in smears from fecal samples or scrapings of intestinal mucosa. It allows the observation of cryptosporidia at low magnification (using a dry lens) and eliminates problems of differential diagnosis related to the presence of yeasts. The method would appear to be easier than the flotation methods recently described by Heine $\&$ Boch and Anderson (1981).

Sv. Aa. Henriksen and J. F. L. Pohlenz

The State Veterinary Serum Laboratory, Copenhagen, and the Department of Veterinary Pathology, Iowa State University, Ames, Iowa. 


\section{REFERENCES}

Anderson, B. C.: Patterns of shedding of cryptosporidial oocysts in Idaho calves. J. Amer. vet. med. Ass. 1981, 178, 982-984.

Angus, K. W., I. Campbell, E. W. Gray \& D. Sherwood: Staining of faecal yeasts and Cryptosporidium oocysts. Vet. Rec. 1981, 93, 173.

Heine, J. \& J. Boch: Kryptosporidien-Infektionen beim Kalb. Nachweis, Vorkommen und experimentelle Ubertragung. (Cryptosporidium infection in the calf. Demonstration, prevalence, and experimental transmission). Berl. Münch. tierärztl. Wschr. 1981, 94, 289-292.

Moon, H.W.\&W. J. Bemrick: Fecal transmission of calf Cryptosporidia between calves and pigs. Vet. Path. 1981, 18, 248-255.

Nagy, B.\& J. Pohlenz: Bovine cryptosporidiosis: A review of literature and first experiments of treatment. Accepted for publication in Tierärztl. Praxis 1981.

Pohlenz, J., H. W. Moon, N. F. Cheville \& W. J. Bemrick: Cryptosporidioses as a probable factor in neonatal diarrhoea of calves. J. Amer. vet. med. Ass. 1978, 172, 452—457.

(Received September 29, 1981).

Reprints may be requested from: Sv. Aa. Henriksen, the State Veterinary Serum Laboratory, 13 Bülowsvej, DK-1870 Copenhagen V, Denmark. 